\title{
Pesticide pollution of the Triassic Sandstone aquifer of South Yorkshire
}

Diffuse pollutants such as pesticides pose a significant threat to groundwater quality. Following the wet autumn and winter of 2000-2001 an upturn in trace pesticide concentrations was detected in blended water drawn from part of the Triassic Sandstone aquifer. A groundwater sampling and monitoring programme was undertaken to assess whether this increase would continue. Over a period of 18 months, 190 groundwater samples were collected from the upper part of the aquifer and analysed for 40 pesticides and for nitrate. A total of 25 pesticides were found of which 16 were detected more than once. Positive pesticide detections were in excess of the EU maximum admissible concentration (MAC) for individual substances of 0.1 $\mu \mathrm{g} \mathrm{l-1}$ on $33 \%$ of occasions. The most commonly detected pesticides generally have higher agricultural application rates and/or relatively greater solubilities. Very high concentrations of mecoprop (up to $7.1 \mu \mathrm{g} \mathrm{l}-1$ ) were consistently found at two of the sampling sites. Analysis of mecoprop enantiomers suggested more than one source for this contaminant. High concentrations of atrazine (up to $1.4 \mu \mathrm{g} l-1$ ) were also detected at three sites and high concentrations of isoproturon $(1.2 \mu \mathrm{g} \mathrm{l}-1)$ were found where very high mecoprop concentrations were also present. Nitrate concentrations exceed the EU MAC of $11.3 \mathrm{mg} \mathrm{l}-1 \mathrm{~N}$ at four sites. The spatial and temporal distribution of pesticides obtained from the monitoring network shows no clear trends for prediction of future concentrations. Nitrate- $\mathrm{N}$ concentrations and pesticide detections show no clear relationship, suggesting different source, transport or degradation pathways.

Key Words: groundwater $\bullet$ pollution $\bullet$ Triassic sandstone aquifer $\bullet$ pesticides $\bullet$ mecoprop • nitrate

\section{Introduction}

Environmental regulators have been concerned with the threat to groundwater from diffuse pollutants such as pesticides and nitrate for at least two decades (Harris \& Skinner 1992). There is a need to better understand the processes by which these contaminants may reach groundwater. Following the wet autumn and winter of 20002001, water levels in many UK aquifers rose to exceptionally high levels and remained high for at least a further year in many regions. Associated with this rise,concentrations of nitrate in abstracted groundwater increased sharply in many parts of the country. Against this national background, Yorkshire Water Plc detected a possible upturn in trace pesticide concentrations in water drawn and blended from different areas within the Triassic Sandstone aquifer of the Doncaster region. In the short term, the potential pesticide problem could be managed by combining waters from areas with low concentrations with those with high concentrations and by the temporary closure of individual boreholes with exceptional concentrations, so that supplied water continued to meet drinking water standards. The available pesticide data comprised measurements made on a few blended sources and so any modelling of possible trends was not practical. To investigate the source of the pesticides and to try and predict future pesticides trends in public supply boreholes a regular, intensive 
pesticide and nitrate sampling regime was initiated at individual private groundwater supplies in the Triassic Sandstone aquifer around the Doncaster area, South Yorkshire.

The European Union (EU) Drinking Water Directive (98/83/EC; European Union 1998) establishes that total pesticide concentration in drinking water must be below $0.5 \mu \mathrm{g} \mathrm{l}-1$ and the concentation must be less than $0.1 \mu \mathrm{g} \mathrm{l}-1$ for a single compound. With effect from December 2003, new limits of $0.03 \mu \mathrm{g} \mathrm{l}-1$ for certain pesticides (aldrin, dieldrin, heptachlor and heptachlor epoxide) have been introduced. Recent UK studies beneath farmed arable land have revealed that pesticide concentrations can exceed these values (Gooddy et al. 2001; Johnson et al. 2001). Increasing numbers of pesticides have been found in groundwaters in the UK (Environment Agency 2003), Europe (Spliid \& Køppen 1998) and North America (Kolpin et al. 1996) as monitoring programmes have been developed. Because of the wide range of pesticide compounds in common usage and the need to work at very low concentrations because of the low regulatory limits, monitoring for pesticides is often costly (Foster et al. 1991). Most groundwater systems in the UK are characterized by relatively slow rates of groundwater flow and contaminant transport, and so the average response period of deep water-supply boreholes to surface inputs, as evidenced by nitrate contamination (Foster et al. 1982), can be of the order of decades. Therefore, analysis of pesticides from deep water-supply boreholes can be an insensitive and tardy indicator of the groundwater quality in the aquifer as a whole.

As a result of the way that some pesticides are synthesized they can consist of a mixture of isomers. For example, the pesticide mecoprop has two enantiomers (identical chemical structure but 'mirror' images of each other), which are distinguished by referring to them as either $\mathrm{R}$ or $\mathrm{S}$ configuration. Commercial mecoprop originally consisted of an equal mixture of the $\mathrm{R}$ and $\mathrm{S}$ forms (termed a 'racemic' mixture). In the 1950s it was recognized that only the $\mathrm{R}$ form was herbicidally active. Since the early 1980s, enantiopure products (with the $\mathrm{R}$ enantiomer only) have been developed and have now replaced the earlier used racemic mixtures. The use of enantiopure products allows lower application rates and so reduces the amounts of trace organic compounds released into the environment. The ratio of one isomer to another can be used diagnostically to give an indication of the source of mecoprop (Harrison et al. 1998; Williams et al. 2003).

In this paper we present pesticide and nitrate data from a groundwater sampling programme of shallow boreholes, carried out over a period of 18 months from January 2002 to June 2003, to investigate the possible source or sources of observed pesticide residues in the public supply boreholes of the Doncaster area. We examine both the range of pesticides present and their relative magnitudes together with assessing the temporal and spatial variability of pesticides and nitrate. Nitrate was sampled as it is a commonly occurring diffuse pollutant, the concentrations of which might be related to those of pesticides, as nitrate concentrations showed an upturn at public water supplies at the same time as the increase in the number of pesticide detections. The overall aim was to determine whether future pesticide concentrations in abstracted groundwater could be predicted, and in particular, whether the rising trend in pesticide concentrations will continue. 


\section{Study area}

\section{Geology}

The bedrock geology of the area comprises Permian and Triassic rocks that dip at 1$2^{\circ}$ to the east and lie unconformably on Carboniferous Coal Measures. The Triassic Sherwood Sandstone Group overlies a mixed sequence of Permian mudstones, marls and siltstones with beds of fine sandstone and seams of gypsum, anhydrite and halite. The Permian forms a largely impermeable base to the Sherwood Sandstone aquifer, which extends to about $300 \mathrm{~m}$ at its deepest point in the east. The Mercia Mudstone Group overlies the Sherwood Sandstone in the east, forming an effective confining horizon (Gaunt 1994).

The Sherwood Sandstone is composed of fining-upwards sequences of breccia, medium- to fine-grained sandstone, silty sandstone, siltstone and marl. The marl is not, however, always present and is often absent towards the top of the unit. The sandstones are generally red or buff coloured, although in places they are grey because of reduction (Smedley et al. 1993). Similarly, the marls show grey to green coloration. A substantial part of the sequence is cross-bedded although parallelbedded, laminated sandstone also frequently occurs. The sandstone is generally poorly cemented and much of the formation is unconsolidated near the surface (Allen et al. 1997).

Quaternary deposits overlie much of the study area and only a small percentage of the Sherwood Sandstone Group crops out at surface. These Drift deposits are very variable, ranging lithologically from peat and clay to gravel. Deposition occurred in glacial, periglacial, fluvial, lacustrine and aeolian environments. The 25-Foot Drift, an expanse of laminated clay with thin lacustrine sands generally occurring around the margins, is of particular importance (Fig. 1). The clay and silts are mainly bluish to reddish-brown and up to 20 m thick. Sands and gravels are important over the entire area and may locally include clays as a minor component. The sand and gravel deposits have been described in detail by Clayton (1979) and Price \& Best (1982).

\section{Hydrogeology}

Drift deposits, particularly in the eastern parts of the area investigated, are of low permeability and act as a locally confining or semi-confining layer (Allen et al. 1997). Consequently, the majority of recharge is believed to occur in the west of the region, although it can also occur through windows in the drift. The drift deposits shown in Figure 1 are only those most likely to affect recharge. Permeability of the sandstone generally decreases from south to north. Porosity values obtained from laboratory tests show the mean to be around 24\% (Allen et al. 1997). Because of increased cementation and overburden, the transmissivity of the confined regions is reduced. A model by Brown \& Rushton (1993) for the Sherwood Sandstone in the Doncaster area showed transmissivity increasing from a minimum of $10 \mathrm{~m} 2$ day-1 at the feather edge to $550 \mathrm{~m} 2$ day- 1 in the centre of the outcrop and then decreasing to $40 \mathrm{~m} 2$ day-1 in the east as the aquifer becomes deeper and confined. This compares with data obtained from a pumping station near the centre of the study area, where a number of boreholes were tested, with transmissivity results ranging from 115 to $880 \mathrm{~m} 2$ day-1 
(Allen et al. 1997). High transmissivities recorded from the study at the pumping station are thought to show the intersection of a fracture system or permeable drift (Dodds 1986). In addition to this, geophysical logging evidence has shown that faults and fractures are widespread in the study area (Buckley 2003), leading to significantly shorter groundwater transit times.

Under natural conditions, groundwater flow would have been easterly, discharging to rivers and wetlands at the east of the outcrop. However, flow directions and gradients have been significantly altered by the effects of large-scale local groundwater abstraction at the public water supply boreholes in the area and modern water levels in the region show a complicated picture with gradients of between 4 and $5 \mathrm{~m} \mathrm{~km}-1$. Today there is broadly radial flow towards a composite cone of depression to the east of Doncaster, in effect replacing shallow lateral drainage with downwards leakage. The depth to the water table has also been significantly increased by abstraction, although is still commonly less than $10 \mathrm{~m}$ (Lapworth et al. 2003).

\section{Hydrochemistry}

Previous sampling in the region (Smedley et al. 1993) showed most groundwaters in the unconfined part of the aquifer to be oxidizing with high redox potentials and appreciable nitrate contents (up to $14 \mathrm{mg} \mathrm{l}-1$ as $\mathrm{N}$ ). It was noted that some samples did have lower redox potentials and were low in nitrate. The confined groundwaters in the area are characterized by the absence of dissolved oxygen and by elevated Fe and Mn concentrations. Ca, Mg, K, SO4 and Sr were also observed to be considerably higher than in samples from the unconfined aquifer. Isotopic and trace element evidence from the study by Smedley et al. (1993) showed that only the confined waters were of Pleistocene age (palaeowaters).

\section{Methods}

\section{Groundwater sampling}

Few of the potential sampling points fulfilled the criteria for the ideal 'sentinel' monitoring point: close to a public supply; small borehole diameter; shallow $(<25 \mathrm{~m})$; and an in situ pump. Access to several otherwise suitable Environment Agency (EA) observation wells was hindered by a sampling orifice designed solely for the measuring of water levels. Therefore, it was decided to sample as many of the licensed abstraction boreholes and available observation wells as possible. All but one of these are shallow with a borehole depth of less than $25 \mathrm{~m}$; the exception is Site 14, where abstraction is from approximately $45 \mathrm{~m}$. During the groundwater sampling period, other sites became available to sample and were added to the regular sampling programme. All sites draw groundwater from within the Sherwood Sandstone aquifer. Sites 3, 8, 10, 11 and 12 required a small, portable submersible pump for sampling as they are not used routinely and contain no fixed pump at the well-head. The submersible pump was capable of pumping at a rate of 0.05-0.1 l s-1. These sites were all pumped so that roughly five volumes of standing borehole water were removed (generally 15-20 min) prior to sampling to ensure a 'fresh' groundwater sample. Sites with fixed pumps commonly had a discharge of 0.5-2 l s-1 and were run to waste for roughly 5 min prior to sampling if they were not already pumping. Sites 4,7 and 14 were removed from the sampling regime after several months of 
monitoring as no pesticides were detected at these sites. Table 1 shows a full list of the sampling sites, their purpose, how often they are used for abstraction and the abstraction volume. Figure 1 shows the site locations in relation to impermeable drift cover. Samples were collected fortnightly from January to April 2002 and then monthly to June 2003.

\section{Groundwater analysis}

Groundwater samples were taken from the sampling point at each of the monitoring sites in three 2.5 litre brown glass bottles. These samples were unfiltered and returned to the analytical laboratory within $24 \mathrm{~h}$ of sampling.

Analysis for a broad spectrum of pesticides was carried out by a United Kingdom Accreditation Service (UKAS) laboratory (SAC Scientific). The pesticides fall into one of four analytical suites: phenoxyacidic pesticides (I), triazine pesticides (II), phenylurea pesticides (III) and carbamate pesticides (IV). Suites I and II required a sample volume of 2 litres whereas suites III and IV required 1 litre. For this sample volume, suites I-III have a reporting limit of $0.020 \mu \mathrm{g} \mathrm{l}-1$ whereas suite IV has a reporting limit of $0.050 \mu \mathrm{g} l-1$.

A breakdown of the compounds covered in each of the analytical suites is given in Table 2. The total volume required for analysis was 6 litres although 7.5 litres were collected for repeats if necessary. A total of 190 samples were taken between January 2002 and June 2003. In addition to the pesticide sample a $7 \mathrm{ml} 0.45 \mu \mathrm{m}$ filtered water sample was taken for nitrate analysis by standard colorimetric methods (Kinniburgh \& Miles 1983).

A one-off sampling for isomers of mecoprop was also carried out at Site 6, Site 1 and a nearby public water supply that had showed elevated concentrations of this pesticide. For enantiomeric determination of mecoprop from the public water supply, samples were collected in two 2.5 litre amber bottles. For the monitoring sites, samples were collected in two $500 \mathrm{ml}$ amber bottles. In each case, sodium azide was added at $0.1 \% \mathrm{w} / \mathrm{v}$ to prevent sample degradation and the samples were refrigerated prior to processing. Samples were pre-concentrated to $2 \mathrm{ml}$ just before analysis. A larger sample volume (and hence concentration factor) was used the public water supply because of the lower concentrations of mecoprop in this sample.

\section{Results and discussion}

The number of pesticides detected and their mean, median and maximum concentrations observed during the sampling period are presented in Table 3. Of the 40 pesticides analysed, 25 were measured above the detection limit, of which 16 were found on more than one occasion. The largest range of pesticides was found at Site 13, where 10 pesticides were found (although no more than five were found in any given sample). The most commonly detected pesticide was mecoprop, followed by bentazone, atrazine and isoproturon. This compares with mecoprop, atrazine, diuron and simazine respectively as the most frequently detected pesticides above $0.1 \mu \mathrm{g} \mathrm{l}-1$ in groundwater found by the UK Environment Agency nationally in 2002 
(Environment Agency 2003). All of the top six most commonly detected pesticides in the present study have also been found at concentrations above the EU maximum admissible concentration (MAC) of $0.1 \mu \mathrm{g} l-1$, with atrazine and isoproturon up to 10 times higher than the MAC and mecoprop more than 70 times above the MAC. Indeed, on $33 \%$ of occasions when pesticides were detected, the measurable concentrations were above the $0.1 \mu \mathrm{g} l-1$ threshold.

Pesticides used for agricultural purposes in the study area have been arranged in terms of water solubility and relative application (Produce Studies Ltd) in Table 4. Compounds with higher solubilities or greater application rates are more commonly detected than those with lower solubilities or lower application rates. Of the eight most frequently detected compounds, six are estimated to be both heavily used for agricultural purposes in the area and relatively mobile with a solubility greater than $100 \mathrm{mg} \mathrm{l}-1$. The exceptions are clopyralid and dicamba, which are less heavily used and have a solubility of less than $8 \mathrm{mg} \mathrm{l}-1$ but are still often detected in the study area (Table 3). However, this simple approach does not take account of amenity herbicide use or other applications, such as wood preservation. This assessment would also suggest that detection of bromoxynil and 2,4-DB might also have been anticipated because of their relatively high usage and application. The absence of these compounds could be due to low subsurface persistence (degradation) or other factors such as point of application and surface drift cover.

\section{Spatial trends in pesticide concentration}

To assess the distribution of pesticides in the study area, the sampling sites have been arranged in order from north to south in Table 5. The frequency of pesticide detection has been normalized to the sampling frequency to eliminate any bias. It should be noted that where this value is greater than one it is indicative of a site where more than one pesticide has been detected. Mecoprop was found over most of the study area with the exception of Sites 4, 5, 7 and 14 (Table 3) but without any clear pattern to its distribution. Indeed, no simple geographical pattern is discernible, with high numbers of detections interspersed by sites where occasional or no detections were found. It is clear by comparison with Figure 1 that no relationship can be established between pesticide concentration or the frequency of pesticide detection and the nature of the drift cover. In terms of assessing the pesticide loading in groundwater for making predictions of future pesticide concentrations at nearby production boreholes, this poses a significant problem.

\section{Temporal data}

Several of the sites monitored showed occasional spikes in pesticide concentration above the detection limit although these spikes did not occur regularly throughout sampling period. Sites 1,6 and 10 showed consistently high concentrations (significantly above the EU MAC) of one or more pesticides and so are dealt with in detail.

\section{Mecoprop}

Mecoprop concentrations at Sites 1 and 6 are shown in Figure 2. The data show very high concentrations of mecoprop. For Site 1, concentrations ranged from 2.4 to $5.2 \mu \mathrm{g}$ 
$\mathrm{l}-1$ (mean and median 3.8 and $3.9 \mu \mathrm{g} \mathrm{l}-1$, respectively). Concentrations remained relatively similar (SD $0.95 \mu \mathrm{g}$ l-1) throughout the sampling period, but exhibited an overall decreasing trend. Concentrations for Site 6 ranged from 0.09 to $7.1 \mu \mathrm{g} \mathrm{l}-1$ (the highest concentration of any pesticide sampled during the study period) with a mean of $3.3 \mu \mathrm{g} \mathrm{l}-1$ and a median of $3.1 \mu \mathrm{g} \mathrm{l}-1$. Concentrations rose rapidly from January 2002 to a peak in early April 2002. Concentrations then fell dramatically but still exceeded $1 \mu \mathrm{g} \mathrm{l}-1$ and a second peak in concentration occurred in January 2003. There was considerably more variation in the concentrations found at Site 6 (SD 1.8 $\mu \mathrm{g}$ l-1). The concentrations found at both of these sites compare with unusually high concentrations detected at a public water supply tapping the Lincolnshire Limestone aquifer (Sweeney et al. 1998), which was found to be associated with a series of landfill sites nearby.

\section{Mecoprop enantiomers}

Mecoprop had previously been found at significant concentrations in a public water supply situated approximately $5 \mathrm{~km} \mathrm{SE}$ of Site 1 and $2 \mathrm{~km}$ south of Site 6. These distances represent groundwater travel times of roughly 40-100 years if only matrix transmissivities are considered, although the travel times are likely to be significantly less because of the presence of fractures and faults (Buckley 2003). To investigate whether mecoprop had a common source, samples were taken from all three sites and analysed for the enantiomers of mecoprop. The results of this sampling are shown in Table 6. The total concentration of mecoprop at Sites 1 and 6 is roughly 60 times higher than at the public water supply but this might be explained by considering the volume of water abstracted by a public supply well and the resultant dilution of a point source contaminant when compared with the much lower volume from a private abstraction well.

The presence of both the $\mathrm{R}$ form and the $\mathrm{S}$ form in all samples indicates that the mecoprop is not enantiopure ( $\mathrm{R}$ form only) and so is likely to be more than 20 years old. The enantiomeric ratios for Sites 1 and 6 are similar and close to one, suggesting racemic mecoprop, whereas the public water supply has an enantiomeric ratio of approximately two, which is probably indicative of a mixture of racemic mecoprop and enantiopure mecoprop. It is therefore suggested that, even if the travel time was less than 20 years, the mecoprop detected at the pumping station does not have the same origin as that at Site 1 or Site 6. It can be inferred that both Sites 1 and 6 may have the same source but from these data alone this cannot be stated unequivocally.

\section{Isoproturon}

Isoproturon concentrations at Site 1 are shown in Figure 3. The data show high concentrations of isoproturon, with a maximum of $1.2 \mu \mathrm{g} \mathrm{l}-1$ (the maximum of the study) and a minimum of $<0.02 \mu \mathrm{g} \mathrm{l}-1$ (mean and median 0.54 and $0.71 \mu \mathrm{g} \mathrm{l}-1$, respectively). This is greater than the concentrations found by Gooddy et al. (2001) in groundwater from the Chalk of southern England, where maximum concentrations of isoproturon of $0.5 \mu \mathrm{g} \mathrm{l}-1$ were measured beneath agricultural land following recent pesticide application, but concentrations of around $0.1 \mu \mathrm{g} \mathrm{l}-1$ were observed at other times of the year. No clear temporal trend exists for isoproturon, with concentrations rising sharply to a high in mid-March $2002(0.98 \mu \mathrm{g} \mathrm{l}-1)$ before falling to the detection limit at the end of March and the end of April and then rising to a relatively 
constant value from June to the end of 2002. The maximum concentration was reached in January 2003.

The patterns for isoproturon and mecoprop appear to be completely different at Site 1 . Figure 4 shows how concentrations of clopyralid and bentazone behave in a similar manner to each other $(\mathrm{R} 2=0.60)$ and show a similar pattern to mecoprop. All three of these compounds are phenoxy acids and are comparable in chemical structure and properties, and hence would be expected to be transported together (Worrall 2001). Fluctuations in the water table cannot explain the observed behaviour, as all four compounds would be expected to peak simultaneously. Preferential degradation of one pesticide relative to another also seems unlikely because of the several peaks in concentration and the relatively slow degradation times observed in aquifer material (Johnson et al. 2003). Isoproturon is considerably less soluble than mecoprop and the other phenoxy acids, and is also more likely to be sorbed to organic matter. Given the relatively shallow unsaturated zone the observed behaviour may relate to preferential flow paths (Foster et al. 1991) and the movement of some pesticide as colloidal material (Grolimund et al. 1996), or it may reflect different times of application and relatively longer soil residence times for isoproturon (Johnson et al. 2001), or indeed a combination of these factors.

\section{Atrazine}

Concentrations of atrazine at Site 10 (mean and median concentrations are $0.49 \mu \mathrm{g} \mathrm{l-}$ 1 and $0.46 \mu \mathrm{g} \mathrm{l}-1$, respectively) rise from below the detection limit $(0.02 \mu \mathrm{g} l-1)$ to an initial peak of $1.0 \mu \mathrm{g} \mathrm{l-1}$ in September 2002, as shown in Figure 5. The concentration drops to the detection limit in December 2002 before gradually increasing again to a maximum of $1.4 \mu \mathrm{g} \mathrm{l}-1$ in June 2003. Groundwater levels from a few dates are available for this site and are also shown in Figure 5. There is an initial relationship that suggests a fall in concentration as the groundwater level falls and then a rise in concentration as the level rises, consistent with atrazine being retained at the top of the profile. This relationship breaks down and the observed pesticide response from October 2002 to January 2003 is more consistent with a dilution effect, a relationship that in itself breaks down as the year progresses. Atrazine is detected only once at Site 11 (at a concentration of $0.59 \mu \mathrm{g} \mathrm{l}-1$ ), which is constructed within $100 \mathrm{~m}$ of, and in a similar manner to, Site 10.

\section{Nitrate}

Nitrate-N data are summarized in Table 5. Generally lower concentrations of NO3-N are found in the east of the region although some of the lowest values occur in the west. At four of the sites the nitrate- $\mathrm{N}$ exceeds the EU MAC of $11.3 \mathrm{mg} \mathrm{l}-1$, and at two of these four sites the values are more than double the EU MAC. The overall mean concentration of nitrate-N was $10.8 \mathrm{mg} \mathrm{l-1}$ (SD $11.1 \mathrm{mg} \mathrm{l-1)}$ ), which gives a coefficient of variation of $103 \%$. This large variation between sites probably reflects the complexity of the drift cover, together with the geology, and land use (Rose et al. 1991).

Figure 6 compares the mean nitrate concentration found at each of the sampling sites with the number of positive pesticide detections for that site normalized to the number of times that site has been visited. There is a paucity of data from which to draw any firm conclusions on a relationship between nitrate concentration and the number of positive detections per sampling; however, there is a trend for lower nitrate-N 
concentrations to be concurrent with more pesticides detected. Low nitrate concentrations may relate to some denitrification caused by reducing conditions as has been suggested previously by Smedley et al. (1993), although that study also suggested that lower nitrate concentrations could result from the presence of larger thicknesses and/or lower permeability drift. On examining the nitrate concentration and the drift cover in the present study (Table 5), no simple relationship between the two can be seen.

For low nitrate to occur with greater number of pesticide detections a preferential route for pesticide movement is implied. It is possible that the pesticide contamination in the study area is emanating from another source such as farm soakaway drainage, which could be high in pesticides and low in nitrate. This might then comprise a series of very small and difficult to identify point sources.

Despite being the most ubiquitous agricultural pollutant, there are perhaps several reasons why nitrate might not act as a suitable surrogate for pesticides: it is a relatively non-sorbing solute; it is applied in a different manner (sometimes in organic form) at different times of the year to pesticides; nitrogen applications have been consistent for many years compared with the ever-changing organic 'cocktail' of pesticides that are applied to different crops; nitrate has a different degradation pathway and redox behaviour to most pesticides; and it is present at concentrations roughly 3-5 orders of magnitude higher than pesticides. Previous work has suggested that under some conditions the risk of pesticide leaching may be increased with a land-use change, if, for example, the number of cultivations on a field is reduced to minimize nitrate leaching (Rose et al. 1991) since cultivation can cause clays to crack leading to the formation of preferential pathways. In addition, a study on clay soils by Johnson et al. (1994) suggested that isoproturon and two inorganic solutes (sulphate and chloride) have different origins in the analysed drain water, with most of the pesticide being carried down to the drainage system by preferential flow from the soil surface.

\section{Conclusions}

Observed pesticide concentrations show considerable variation, which probably relates to a complex combination of land use, pesticide use, drift cover (type and distribution) and geology. Little correlation was found between pesticides detected at the same site, the exception being bentazone, clopyralid and mecoprop at Site 1. At the same site no correlation was found with isoproturon. From monitoring nitrate and 40 pesticides in the study area over a period of 18 months, no discernible trends could be identified, either spatially or temporally. Using nitrate data as a proxy for pesticide data in this study area is not appropriate because of different application times and rates, transport and transformation mechanisms, and potentially different sources.

Investigating mecoprop by enantiomeric methods at three sites suggested more than one source of mecoprop. This raises the considerable problem of trying to identify whether or not the contaminant comes from a point source, multiple point sources or is a diffuse contaminant. From the range of concentrations and the breadth of pesticides detected, and in particular the frequency of mecoprop detection at 10 of the 
14 sampling sites, it is suggested that there is a diffuse, relatively low background concentration of pesticides within the Triassic sandstone aquifer of South Yorkshire, whereas high concentrations of atrazine, isoproturon and, most notably, mecoprop are more consistent with origination from one or more unidentified point sources.

In establishing a monitoring network for pesticides, the difficulty in finding suitable, 'representative' sites and the problems of heterogeneity have become apparent. Other studies, which have operated on the much smaller experimental plot scale (Gooddy et al. 2002) or field scale (Gooddy et al. 2001; Johnson et al. 2001), have also found considerable difficulty in interpreting trends and processes because of the heterogeneity of the subsurface in shallow groundwater systems in the UK. These contrast with the relatively much more homogeneous land use and hydrogeological conditions found in the USA. There, much lower sampling densities have been used by Kolpin et al. (1996) to provide a comprehensive picture of pesticide distribution in an extensive aquifer beneath relatively uniform land use dominated by maize cultivation. Implementing a monitoring network using existing abstraction points and observation wells and analysing for a broad spectrum of pesticide is a costly operation at the sampling density used in this study, but still does not provide enough data to represent the spatial and temporal distribution within the much more complex land use and hydrogeological conditions of the present study area. It certainly does not provide adequate data for predicting future pesticide concentrations at public supply boreholes. It is unlikely that a sufficient network could be established to minimize the uncertainties resulting from this spatial heterogeneity and to take into account the impacts of a potential change in recharge (see, e.g. Bloomfield et al. 2003) within an economically viable budget or the time frame of a water company asset management plan. Future studies may need to focus on a smaller range of compounds and invest resources in a higher density of sampling sites by constructing observation wells, although such an approach is problematic if a key pesticide turns out to have been omitted from the sampling suite, and monitoring will still need to be carried out over several years to establish any trends.

\section{Acknowledgements}

This work was funded by Yorkshire Water Plc. This paper is published with the permission of the Executive Director of the British Geological Survey (NERC). The study would not have been possible without the consent of the many landowners in the survey area, who are gratefully acknowledged. We would like to thank A. Binley for facilitating access to the Lancaster University research borehole. The authors would also like to thank D. Allen, S. Hannay and J. Trafford of BGS Wallingford for assistance with the field sampling, I. Harrison of BGS Keyworth for analytical work carried out on mecoprop enantiomers, and R. Hargreaves from BGS Wallingford for the drafting of Figure 1. A. Williams and D. Buckley of BGS Wallingford provided helpful discussions and insights during the revision of this manuscript.

\section{References}

Allen, D.J., Brewerton, L.J., Coleby, L.M., Gibbs, B.R., Lewis, M.A., Wagstaff, S.J., Williams, A.T., The Physical Properties of Major Aquifers in England and Wales. British Geological Survey Report, WD/97/34 1997. 
Bloomfield, J.P., Gaus, I., Wade, S.D., A method for investigating the potential impacts of climate-change scenarios on annual minimum groundwater levels. Water and Environmental Management Journal, 17 2003. 86-91.

Brown, I.T., Rushton, K.R., Modelling of the Doncaster aquifer. Final report for Yorkshire Water Services and NRA Severn-Trent Region 1993.

Buckley, D.K. Pesticides in the Triassic Sandstone Aquifer of South Yorkshire: Interpretation of Boreholes Geophysical Logging. British Geological Survey Report, CR/03/071C 2003.

Clayton, A.R. The sand and gravel resources of the country around Bawtry, South Yorkshire. Institute of Geological Sciences, Mineral Assessment Report, 371979.

Dodds, J.E. 1986. The hydrogeology of Nutwell Pumping Station, South Yorkshirea reappraisal. MSc thesis, University College London.

E nvironment Agency Pesticides 2002: a Summary of Monitoring of the Aquatic Environment in England and Wales., 2003. Environment Agency, Bristol.

European Union 1998. European Union Drinking Water Directive (98/83/EC), Official Journal of the European Communites 5 December 1998. L330/32-330/54.

Foster, S.S.D., Cripps, A.G., Smith-Carington, A.K., Nitrate leaching to groundwater. Philosophical Transactions of the Royal Society of London, 296 1982. 477-489.

Foster, S.S.D., Chilton, P.J., Stuart, M.E., Mechanisms of groundwater pollution by pesticides. Journal of the Institution of Water and Environmental Management, 5 1991. 186-193.

Gaunt, G.D. Geology of the Country Around Goole, Doncaster and the Isle of Axholme. Memoir of the British Geological Survey, Sheets 79 and 88 (England and Wales) 1994.

Gooddy, D.C., Bloomfield, J.P., Chilton, P.J., Johnson, A.C., Williams, R.J., Assessing herbicide concentrations in the saturated and unsaturated zone of a Chalk aquifer in Southern England. Ground Water, 39 2001. 262-271

Gooddy, D.C., Chilton, P.J., Harrison, I., A field study to assess the degradation and transport of diuron and its metabolites in a calcareous soil. Science of the Total Environment, 297 2002. 67-83.

Grolimund, D., Borkovec, M., Barmettler, K., Sticher, H., Colloid-facillitated transport of strongly sorbing contaminants in natural porous media: a laboratory column study. Environmental Science and Technology, 30 1996. 3118-3123.

Harris, R.C., Skinner, A.C., Controlling diffuse pollution of groundwater from agriculture and industry. Journal of the Institution of Water and Environmental Management, 6 1992. 569-575. 
Harrison, I., Leader, R.U., Higgo, J.J.W., Williams, G.M., A study of the degradation of phenoxy acid herbicides at different sites in a limestone aquifer. Chemosphere, 36 1998. 1211-1232.

Johnson, A.C., Haria, A.H., Bhardwaj, C.L., Volkner, C., Batchelor, C.H., Watermovement and isoproturon behavior in a drained heavy clay soil. 2. Persistence and transport. Journal of Hydrology, 163 1994. 217-231.

Johnson, A.C., Besien, T.J., Bhardwaj, C.L., Dixon, A., Gooddy, D.C., Haria, A.H., White, C., Penetration of herbicides to groundwater in an unconfined chalk aquifer following normal soil applications. Journal of Contaminant Hydrology, 53 2001. 101117.

Johnson, A.C., White, C., Bhardwaj, C.L., Dixon, A., The ability of indigenous micro-organisms to degrade isoproturon, atrazine and mecoprop within aerobic UK aquifer systems. Pesticide Management Science, 59 2003. 1291-1302.

Kinniburgh, D.G., Miles, D.L., Extraction and chemical analysis of interstitial water from soil and rocks. Environmental Science and Technology, 17 1983. 362-368.

Kolpin, D.W., Thurman, E.M., Goolsby, D.A., Occurrence of selected pesticides and their metabolites in near-surface aquifers of the Midwestern United States. Environmental Science and Technology, 30 1996. 335-340.

Lapworth, D.J., Gooddy, D.C., Stuart, M.E., Pesticides in the Triassic Sandstone Aquifer of South Yorkshire: Groundwater Monitoring Jan 2002-Nov 2003. British Geological Survey Report, CR/03/278C 2003.

Price, D., Best, D.P., The sand and gravel resources of the country around Armthorpe, South Yorkshire. Institute of Geological Sciences, Mineral Assessment Report, 92 1982.

Rose, S.C., Harris, G.L., Armstrong, A.C., Williams, J.R., Howse, K.R., Tranter, N., The leaching of agrochemicals under different land uses and its effect on water quality. In: Peters, N.E. \& Walling, D.E. (eds) Sediment and Stream Water Quality in a Changing Environment: Trends and Explanation. IAHS Publications, 2031991. 249-257.

Smedley, P.L., Shand, P., Edmunds, W.M., Hydrogeochemistry of the Sherwood Sandstone aquifer of the Doncaster area. British Geological Survey Report, WD/93/41 1993.

Spliid, N.H., Køppen, B., Occurrence of pesticides in Danish shallow groundwater. Chemosphere, 37 1998. 1307-1316.

Sweeney, J., Hart, P.A., McConvey, P.J., Investigation and management of pesticide pollution in the Lincolnshire Limestone aquifer in eastern England. In: Mather, J., Banks, D., Dumpleton, S. \& Fermor, M. (eds) Groundwater Contaminants and their Migration. Geological Society, London, Special Publications, 128 1998. 347-360. 
Williams, G.M., Harrison, I., Carlick, C.A., Crowley, O., Changes in enantiomeric fraction as evidence of natural attenuation of mecoprop in a limestone aquifer. Journal of Contaminant Hydrology, 63 2003. 253-267.

Worrall, F.A molecular topology approach to predicting pesticide pollution of groundwater. Environmental Science and Technology, 35 2001. 2282-2287. 